\title{
Atributos químicos de um Neossolo Quartzarênico de cerrado sob diferentes sistemas de uso e manejo
}

\author{
Taine Pereira de Oliveira ${ }^{1}$, Simone Cândido Ensinas ${ }^{1}$, Giselle Feliciani Barbosa ${ }^{1}$, Marina \\ Chiquito Nanzer ${ }^{1}$, Paulo Gabriel Vechetin Barreta ${ }^{1}$

\begin{abstract}
${ }^{1}$ Universidade Estadual de Mato Grosso do Sul, Unidade Universitária de Cassilândia, Cassilândia, Mato Grosso do Sul, Brasil. Email: tainepoliveira96@gmail.com, simone-ensinas@uems.br, gisellefeliciani@gmail.com, marina_nanzer@hotmail.com, paulo.barreta@gmail.com
\end{abstract}

Recebido: 27/10/2017; Aceito: 01/11/2017.

\section{RESUMO}

Os Neossolos são solos com baixa fertilidade natural, porém, as formas de uso e manejo do solo podem alterar seus atributos químicos do solo, com isso objetivou-se quantificar os teores de pH, H+Al, Al, Ca, Mg, $\mathrm{P}$ e $\mathrm{K}$ e calcular a SB, CTC, m\% e V\% num Neossolo Quartzarênico sob vegetação nativa, seringueira solteira, seringueira consorciada com abacaxi, pastagem de Brachiaria sp. com 30 anos, pastagem de Brachiaria brizanta cv. Marandu com 3 anos e área de plantio convencional. As amostras de solo foram coletadas em Cassilândia-MS nas camadas de 0-10, 10-20 e 20-30 cm. Os resultados foram submetidos à análise de variância e quando significativa, as médias dos tratamentos foram agrupadas pelo teste de Scott-Knott $(\mathrm{p} \leq 0,05)$. O sistema de pastagem com 3 anos apresentou melhores resultados nos atributos químicos obtendo maiores valores de $\mathrm{pH}, \mathrm{Ca}, \mathrm{Mg}, \mathrm{K}, \mathrm{P}, \mathrm{SB}$ e $\mathrm{V} \%$, além dos menores valores de $\mathrm{H}+\mathrm{Al}, \mathrm{Al}$ e $\mathrm{m} \%$. A área de vegetação nativa apresentou acidez ativa e os teores $\mathrm{H}+\mathrm{Al}, \mathrm{Al}$ e m\% mais elevados. Os Neossolos Quartzarênicos do Cerrado apresentam baixa fertilidade natural e a variação dos atributos químicos estão relacionados principalmente com o manejo da adubação. Desta forma, recomenda-se realizar correções e adubações regularmente nestes solos para produção agrícola.

Palavras-chave: Manejo sustentável, fertilidade do solo e qualidade do solo.

\section{Chemical attributes of a Cerrado Quartzarenic Neosol under different use and management systems}

\section{ABSTRACT}

The Quartzarenic Entisol (Entisol) are soils with low natural fertility, but the forms of soil use and soil management can alter the chemical attributes of the soil, with the aim of quantifying the $\mathrm{pH}, \mathrm{H}+\mathrm{Al}, \mathrm{Al}, \mathrm{Ca}, \mathrm{Mg}, \mathrm{P}$ and $\mathrm{K}$ and to calculate the BS, CEC, $\mathrm{m} \%$ and V\% in a Quartzarenic Entisol (Entisol) under native vegetation, single rubber tree, rubber tree intercropped with pineapple, Brachiaria sp. with 30 years, pasture of Brachiaria brizanta cv. Marandu with 3 years and conventional planting area. Soil samples were collected in Cassilândia-MS in the 0-10, 10-20 and 20-30 cm layers. The 3-year-old grazing system presented better results in the chemical attributes obtaining higher values of $\mathrm{pH}, \mathrm{Ca}, \mathrm{Mg}, \mathrm{K}, \mathrm{P}, \mathrm{BS}$ and $\mathrm{V} \%$, besides the lower values of $\mathrm{H}+\mathrm{Al}, \mathrm{Al}$ and $\mathrm{m} \%$. The native vegetation area showed active acidity and $\mathrm{H}+\mathrm{Al}, \mathrm{Al}$ and $\mathrm{m} \%$ higher levels. The Quartzarenic Entisol (Entisol) of the Cerrado present low natural fertility and the variation of the chemical attributes are related mainly to the management of the fertilization. In this way, it is recommended to make corrections and fertilizations regularly in these soils for agricultural production.

Key words: Sustainable management, soil fertility and soil quality. 


\section{Introdução}

Os Neossolos Quartzarênicos são originados de reservas arenosas e apresentam textura de areia ou areia franca até $2 \mathrm{~m}$ de profundidade. Embora sejam declarados como de baixa aptidão agrícola, a demanda por novas áreas destinadas à agropecuária, após a década de 70, resultou na incorporação desses tipos de solo para o sistema de pastagem, e subsequente processo de produção de grãos (FRAZÃO et al., 2008).

Os solos desta classe apresentam grande deficiência de cálcio, magnésio e fósforo e, aliando-se à elevada concentração de alumínio, apresentam grande limitação para o cultivo de espécies vegetais, sendo necessário o uso intensivo de corretivos e fertilizantes. Carneiro et al. (2009) comparando as variações de pH em um Neossolo Quartzarênico Órtico cultivado com Cerrado nativo, pastagem nativa, integração agriculturapecuária, pastagem cultivada, soja e milho em plantio direto observaram que os valores de $\mathrm{pH}$ não diferiram entre os sistemas de uso do solo e, que a erosão e a lixiviação, presentes neste solo, ocasionaram a perda de potássio $\left(\mathrm{K}^{+}\right)$. No mesmo trabalho, os autores constataram também que as áreas sob vegetação de Cerrado nativo apresentaram maior teor de $\mathrm{H}+\mathrm{Al}_{\text {e }} \mathrm{Al}^{3+}$ e menores teores de $\mathrm{Ca}, \mathrm{Mg}$ e $\mathrm{P}$, em relação as áreas manejadas, sendoe aceitável visto que na área não foram realizadas as correções e adubações do solo, tratando-se de solos originalmente distróficos.

Portugal et al. (2007) estudando o efeito de diferentes usos agrícolas do solo concluíram que as características químicas dos solos com mata, seringueira e pastagem apresentam baixos níveis de fertilidade e caráter distrófico, com $\mathrm{Al}^{3+}$ trocável dominando o complexo de troca. No entanto, as áreas de mata e seringueira por proporcionarem maior adição de resíduos vegetais ao solo, podem contribuir para maior ciclagem de nutrientes e complexar o alumínio tóxico as plantas.

Os Neossolos também são solos muito dependentes da quantidade de matéria orgânica do solo (MOS) que, em combinação com a caulinita e os óxidos de ferro e alumínio, constituem as superfícies de cargas negativas, sendo assim, a MOS é responsável por 75 a $85 \%$ da CTC (SIQUEIRA NETO et al., 2009).

A utilização intensa dos Neossolos com culturas anuais pode promover rápida degradação do solo. Entretanto, o manejo correto que visa reduzir a erosão e as perdas de solo e nutrientes, otimizar a biodiversidade diminuindo a incidência de pragas e doenças, preservando e/ou elevando os teores de MOS, pode melhorar o seu potencial produtivo em um curto prazo (FRAZÃO et al., 2008).

Estudos mostram que a degradação do Cerrado, por meio de queimas e derrubadas sob diferentes sistemas de manejo pode ocasionar a diminuição da
MOS, da fertilidade do solo e provocar o aumento da erosão. Áreas convertidas em pastagens com ausência de manejo, consequentemente apresentam níveis baixos de MOS em relação à vegetação nativa, com reduzida ciclagem de nutrientes (SOUZA et al., 2008; VOLPE et al., 2008). O mesmo ocorre em áreas com sistema de plantio convencional devido ao revolvimento contínuo do solo que favorece a decomposição da MOS e a menor ciclagem de nutrientes (ARAÚJO et al., 2007; SIQUEIRA NETO et al., 2009).

Entretanto, em áreas de pastagens manejadas, os teores de MOS superam os encontrados em áreas de vegetação nativa (SIQUEIRA NETO et al., 2009). No sistema plantio direto também tem se observado incrementos nos teores de MOS, devido ao nãorevolvimento do solo, rotação de culturas e a manutenção dos resíduos culturais na sua superfície, proporcionando assim maiores valores de potássio, fósforo, cálcio e magnésio na camada superficial do solo (SANTOS; TOMM, 2003).

Levando em consideração o fato que cada sistema de uso e manejo do solo pode promover mudanças nos atributos químicos do solo e sendo limitado o número de pesquisas na região, este trabalho teve como objetivo quantificar os teores de $\mathrm{pH}, \mathrm{H}+\mathrm{Al}, \mathrm{Al}, \mathrm{Ca}$, $\mathrm{Mg}, \mathrm{P}, \mathrm{K}, \mathrm{SB}, \mathrm{CTC}, \mathrm{m} \%$ e V\% num Neossolo Quartzarênico sob diferentes sistemas de uso e manejo.

\section{Material e Métodos}

O experimento foi realizado na Universidade Estadual de Mato Grosso do Sul, Unidade Universitária de Cassilândia, nas coordenadas geográficas: $51^{\circ} 43^{\prime} 15^{\prime \prime} \mathrm{W}, 19^{\circ} 07^{\prime} 21^{\prime \prime} \mathrm{S}$, com altitude média de 520 $\mathrm{m}$. O solo das áreas onde os sistemas de uso e manejo do solo estão localizados é classificado como Neossolo Quartzarênico Órtico (SANTOS et al., 2013). O clima da região é classificado segundo Köppen (1948) como clima tropical chuvoso (Aw) apresentando verão chuvoso e inverno seco com precipitação menor que 60 $\mathrm{mm}$.

Para avaliar os sistemas de uso e manejo do solo, foram coletadas amostras de seis áreas, sendo elas: área de vegetação nativa de cerrado, formada por uma área de vegetação natural, caracterizada como área de reserva, separada a uma distância de $300 \mathrm{~m}$ das áreas em estudo; a área de seringueira cultivada por 20 anos sem manejo de fertilidade do solo; a área de seringueira (Hevea brasiliensis) consorciada com abacaxi (Ananas comosus) cultivada por seis anos de seringueira com aplicação de $2 \mathrm{t} \mathrm{ha}^{-1}$ de calcário e adubação realizada de acordo com as recomendadas para as culturas; área de pastagem com trinta anos cultivada com Brachiaria brizantha cv. Marandu por trinta anos sob pastejo 
semi-intensivo, com manejo esporádico da fertilidade do solo; área de pastagem com três anos também cultivada com Brachiaria brizantha cv. Marandu com manejo de fertilidade do solo e ausência de pastejo na área, sendo anteriormente ocupada com pastagem degradada; área de plantio convencional cultivada com amendoim (Arachis hypogaea) recebendo aplicação de $2 \mathrm{t} \mathrm{ha}^{-1}$ de calcário e adubação realizada com $900 \mathrm{~kg}$ $\mathrm{ha}^{-1}$ do adubo formulado 4-14-8. Nesta área, anteriormente ocupada por pastagem degradada, as amostras foram coletadas após a colheita do amendoim. Cada sistema de uso e manejo do solo foi subdivido em quatro áreas que representavam as repetições e, nelas foram realizadas as coletas de solo com auxílio de um trado holandês nas camadas de 010, 10-20, 20-30 cm para determinação dos atributos químicos. As amostras coletadas foram secas ao ar, destorroadas e passadas em peneiras com malha de 2,0 $\mathrm{mm}$.

Os atributos químicos foram determinados segundo metodologias descritas por Claessen (1997). Após a determinação dos teores dos nutrientes foi realizado o cálculo da soma de bases (SB), saturação por bases (V\%) e capacidade de troca de cátions a pH 7,0 (CTC). Os atributos químicos avaliados, em cada camada, foram submetidos à avaliação de normalidade dos dados (Lilliefors) e posteriormente os resultados foram submetidos à análise de variância e quando significativa, as médias dos tratamentos foram agrupadas pelo teste de Scott-Knott $(\mathrm{p} \leq 0,05)$.

\section{Resultados e Discussão}

As variáveis referentes à acidez do solo $(\mathrm{pH}, \mathrm{H}+\mathrm{Al}$ e $\mathrm{Al}^{3+}$ ) nas três camadas estudadas apresentaram diferença estatística a $1 \%$ de probabilidade entre os distintos sistemas de uso e manejo do solo (Tabela 1). O solo em sistema de vegetação nativa $(\mathrm{VN})$ registrou acidez muito elevada e pobreza em bases, decorrente da sua baixa fertilidade natural.

Carvalho et al. (2015) avaliando as alterações ocorridas nos atributos físicos e químicos de um Neossolo Quartzarênico a partir de seus diferentes sistemas de uso e manejo, sendo eles floresta de eucalipto, pastagem extensiva, integração lavourapecuária, integração lavoura-pecuária-floresta e uma área de vegetação nativa de Cerrado, também constataram elevada acidez na área de vegetação nativa de Cerrado, nas profundidades 0-5, 5-10 e 10-20 cm. Os valores obtidos para o $\mathrm{pH}$ do solo indicam que apenas a área de pastagem reformada com 3 anos (PAST-3) apresentou pH classificado como bom, ou seja, pH na faixa de 5,5-6,0 (RIBEIRO et al. 1999).
Na camada de 0-10 cm, a área PAST-3 apresentou o maior valor de $\mathrm{pH}$, seguido da área de plantio convencional (PC) e pastagem com 30 anos (PAST30). Nestas áreas, a correção do solo foi realizada mais recentemente, o que indica o benefício da calagem na neutralização do $\mathrm{H}^{+}$. Resultados semelhantes foram obtidos por Costa et al. (2015) ao avaliarem os atributos químicos de um Latossolo Vermelho e um Argissolo Vermelho-Amarelo da sub-bacia Jardim Novo Horizonte no Noroeste do Estado de São Paulo, submetidos aos usos com a cultura da manga, sendo quatro locais com pastagem e a cultura do milho no Latossolo e dois locais com pastagem, cultura do milho e área com fragmento de mata no Argissolo. Os autores observaram menor acidez nas áreas com culturas anuais e nas pastagens em relação ao solo sob vegetação natural de cerrado ou cultura perene, justamente devido à correção dos solos nas áreas cultivadas.

Tabela 1. Valores de $\mathrm{pH} \mathrm{CaCl}_{2}, \mathrm{H}+\mathrm{Al}$ e $\mathrm{Al}^{3+}$ em diferentes sistemas de uso do solo. Cassilândia-MS, 2017

\begin{tabular}{|c|c|c|c|}
\hline Sistemas & $\begin{array}{c}\mathrm{pH} \\
\mathrm{CaCl}_{2}\end{array}$ & \multicolumn{2}{|c|}{$-\mathrm{Cmol}_{\mathrm{C}} \mathrm{dm}^{-3}$} \\
\hline & \multicolumn{3}{|c|}{$0-10 \mathrm{~cm}$} \\
\hline VN & $4,49 \mathrm{D}$ & $7,61 \mathrm{~A}$ & $1,95 \mathrm{~A}$ \\
\hline SS & $4,58 \mathrm{D}$ & $5,72 \mathrm{~B}$ & $1,17 \mathrm{~B}$ \\
\hline SCA & $4,96 \mathrm{D}$ & $5,32 \mathrm{~B}$ & $1,01 \mathrm{~B}$ \\
\hline PAST-30 & $5,13 \mathrm{C}$ & $4,34 \mathrm{C}$ & $0,60 \mathrm{C}$ \\
\hline PAST-3 & $6,01 \mathrm{~A}$ & $2,82 \mathrm{D}$ & $0,22 \mathrm{C}$ \\
\hline $\mathrm{PC}$ & $5,46 \mathrm{~B}$ & $4,07 \mathrm{C}$ & $0,50 \mathrm{C}$ \\
\hline Teste F & $23,03 * *$ & $19,84 * *$ & $29,95 * *$ \\
\hline \multirow[t]{2}{*}{$\mathrm{CV} \%$} & 4,64 & 14,78 & 24,67 \\
\hline & \multicolumn{3}{|c|}{$10-20 \mathrm{~cm}$} \\
\hline$\overline{\mathrm{VN}}$ & $4,52 \mathrm{C}$ & $6,74 \mathrm{~A}$ & $1,55 \mathrm{~A}$ \\
\hline SS & $4,59 \mathrm{C}$ & $5,64 \mathrm{~B}$ & $1,40 \mathrm{~A}$ \\
\hline SCA & $4,87 \mathrm{~B}$ & $5,41 \mathrm{~B}$ & $1,15 \mathrm{~B}$ \\
\hline PAST-30 & $5,10 \mathrm{~B}$ & $4,11 \mathrm{C}$ & $0,62 \mathrm{C}$ \\
\hline PAST-3 & $5,84 \mathrm{~A}$ & $2,96 \mathrm{D}$ & $0,17 \mathrm{D}$ \\
\hline $\mathrm{PC}$ & $5,06 \mathrm{~B}$ & $4,36 \mathrm{C}$ & $0,97 \mathrm{~B}$ \\
\hline Teste F & $34,29 * *$ & $18,85^{* *}$ & $25,99 * *$ \\
\hline \multirow[t]{2}{*}{$\mathrm{CV} \%$} & 3,24 & 12,60 & 20,46 \\
\hline & \multicolumn{3}{|c|}{$20-30 \mathrm{~cm}$} \\
\hline $\mathrm{VN}$ & $4,56 \mathrm{~B}$ & $5,92 \mathrm{~A}$ & $1,45 \mathrm{~A}$ \\
\hline SS & $4,60 \mathrm{~B}$ & $5,56 \mathrm{~A}$ & $1,27 \mathrm{~A}$ \\
\hline SCA & $4,82 \mathrm{~B}$ & $5,43 \mathrm{~A}$ & $1,12 \mathrm{~A}$ \\
\hline PAST-30 & $5,23 \mathrm{~A}$ & $3,96 \mathrm{C}$ & $0,70 \mathrm{~B}$ \\
\hline PAST-3 & $5,60 \mathrm{~A}$ & $3,10 \mathrm{D}$ & $0,30 \mathrm{C}$ \\
\hline $\mathrm{PC}$ & $4,52 \mathrm{~B}$ & $4,70 \mathrm{~B}$ & $1,42 \mathrm{~A}$ \\
\hline Teste F & $10,20 * *$ & $14,54 * *$ & $15,11 * *$ \\
\hline CV\% & 5,60 & 11,85 & 22,45 \\
\hline
\end{tabular}

(Vegetação nativa), SS (seringueira solteira), SCA (seringueira consorciada com abacaxi), PAST-30 (área de pastagem com 30 anos), PAST-3 (área de pastagem reformada a 3 anos) e PC (área de plantio convencional). Médias seguidas de letras iguais na coluna não diferem entre si pelo teste de Scott-Knott $(\mathrm{p} \leq 0,05)$. Pelo Teste F **significativo a $1 \%$ de probabilidade, *significativo a $5 \%$ de probabilidade, ${ }^{\text {ns }}$ não significativo. 
Tratanto-se da acidez potencial $(\mathrm{H}+\mathrm{Al})$ dos sistemas de manejo do solo, o sistema PAST-3 apresentou menores valores em todas as camadas. A menor acidez potencial observada na PAST-3 ocorreu devido à adição de calcário que fornece ânions $\mathrm{OH}$ e $\mathrm{HCO}_{3}{ }^{-}$receptores de $\mathrm{H}^{+}$, liberando assim, os coloides disponíveis para a ligação de $\mathrm{Ca}^{2+}$ e $\mathrm{Mg}^{2+}$, onde anteriormente eram ocupados por $\mathrm{H}^{+}$e $\mathrm{Al}^{+}$(CAIRES, 2010). Na área de PAST-3, os teores de $\mathrm{H}+\mathrm{Al}$ são classificados como médios, já nas áreas de VN, SS e SCA os teores de $\mathrm{H}+\mathrm{Al}$ se enquadram como alto $(\geq 5,1$ $\mathrm{cmol}_{\mathrm{c}} \mathrm{dm}^{-3}$ ) segundo classificação de Ribeiro et al. (1999).

Observando os teores de alumínio na Tabela 1, nota-se que nas três camadas, os maiores teores de $\mathrm{Al}^{3+}$ foram verificados na área de $\mathrm{VN}$ em relação aos demais sistemas de uso, sendo classificados como altos $\left(\geq 1,01 \mathrm{cmol}_{\mathrm{c}} \mathrm{dm}^{-3}\right.$ ) (RIBEIRO et al. 1999). Isso se deve principalmente pelo fato de tratar-se de um solo originalmente distrófico (CARNEIRO et al., 2009) e, por ser uma área caracterizada como área de reserva não submetida a correções. Já os menores teores deste atributo foram observados no sistema PAST-3, onde os valores de alumínio estão baixos. Estes resultados podem ser explicados devido ao manejo da fertilidade do solo, mais especificamente pelos efeitos proporcionados pela elevação do $\mathrm{pH}$, na neutralização deste elemento (SOUZA e ALVES, 2003) e a ausência de pastejo, que poderia causar intensa degradação desta área. Os teores de cálcio, magnésio, potássio e fósforo apresentaram diferença estatística a $1 \%$ de probabilidade nos sistemas de uso e manejo do solo para todas as camadas (Tabela 2).

Com relação aos teores de cálcio, a área de VN e SS apresentaram os menores teores do elemento em todas as camadas avaliadas diferindo estatisticamente dos demais sistemas (Tabela 2). Os teores de cálcio observados nestes sistemas estão abaixo de 4,0 $\mathrm{cmol}_{\mathrm{c}} \mathrm{dm}^{-3}$, indicando teores baixíssimos segundo Ribeiro et al. (1999). Estes resultados são em decorrência da ausência de manejo da fertilidade do solo, visto que não houve aplicação de corretivos nestas áreas.

Nas três camadas, os maiores teores de cálcio foram verificados na área de PAST-3 e PC, fato que se deve à realização do manejo da fertilidade do solo. Tais resultados se assemelham aos obtidos por Siqueira Neto et al. (2009) que, estudando os atributos químicos de um Latossolo Vermelho distrófico no Cerrado sob áreas de cerradão, pastagem de baixa produtividade, plantio convencional de soja e plantio direto de soja com milho em sucessão, observaram maiores teores de cálcio no plantio convencional e no plantio direto, principalmente na camada superficial.
Para o teor de Mg, a PAST-3 apresentou os maiores teores nas três camadas, diferindo estatisticamente dos demais sistemas na camada de 10-20 e 20-30 cm, porém, na camada de $0-10 \mathrm{~cm}$ não apresentou diferença com relação à seringueira consorciada com abacaxi (SCA). Isso pode ser atribuído à aplicação e incorporação de calcário na área, o que promove uma

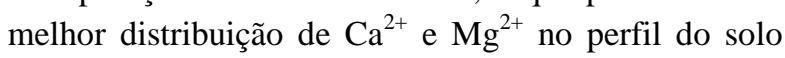
(MATIAS et al., 2009) e ao aumento da CTC efetiva do solo (SOUZA; ALVES, 2003).

Apenas a área de PAST-3 apresentou nas camadas de 0-10 e 10-20 cm, teores de magnésio enquadrados como médios $\left(0,46-0,90 \mathrm{cmol}_{\mathrm{c}} \mathrm{dm}^{-3}\right)$. Nos demais sistemas os teores de magnésio estão enquadrados com baixo a muito baixo (RIBEIRO et al. 1999). Tal característica pode ser considerada como uma resposta esperada para este tipo de solo e manejo, em que a contribuição da vegetação para o suprimento deste nutriente é pequena (FRAZÃO et al., 2008).

Para o potássio, os teores observados nos sistemas de uso encontram-se com valores médios $(0,105$ $\left.0,180 \mathrm{cmol}_{\mathrm{c}} \mathrm{dm}^{-3}\right)$ e na sua maioria com valores baixos $\left(\leq 0,038 \mathrm{cmol}_{\mathrm{c}} \mathrm{dm}^{-3}\right.$ ) (RIBEIRO et al., 1999). Sendo que os maiores teores foram constatados na SCA, PAST-3 e PC em todas as camadas estudadas diferindo significativamente dos demais sistemas de uso do solo. Costa et al. (2005), relataram que os maiores valores de $\mathrm{K}$ observados na seringueira quando em consórcio são decorrentes da ciclagem de nutrientes, proveniente da serrapilheira, uma vez que plantas mais velhas contribuem de forma mais acentuada para $o$ fornecimento deste nutriente devido a maior queda de folhas e consequente formação de matéria orgânica. Nas áreas de PAST-3 e PC, os maiores teores de K são resultados do manejo da adubação realizada.

Os sistemas PAST-3 e PC apresentaram os maiores teores de fósforo sendo superiores estatisticamente em relação aos demais sistemas de uso na camada de 0-10 e 10-20 cm. Na camada de 20-30 cm, estes sistemas não apresentaram diferenças significativas em relação à SCA e PAST-30. Podem-se relacionar tais valores à realização do manejo da fertilidade na PAST-3 e à aplicação de fertilizantes fosfatados no PC.

Todos os teores de $\mathrm{P}$ observados nas camadas $0-10$, 10-20 e 20-30 cm, nos sistemas de uso do solo são considerados baixos $\left(<20 \mathrm{mg} \mathrm{dm}^{-3}\right)$, com exceção do PC na camada de $10-20 \mathrm{~cm}$ que apresentou teor classificado como médio (RIBEIRO et al., 1999). Os baixos teores de $\mathrm{P}$ nos solos de cerrado são causados pela sua fixação no solo, visto que, a mineralogia dos solos de cerrado é formada por caulinita e óxidos, hidróxidos de ferro e alumínio gerando grande quantidade de carga positiva no solo, o que contribui para absorção e posteriormente fixação do ânion de P. 
Tabela 2. Valores de cálcio (Ca), magnésio $(\mathrm{Mg})$, potássio $(\mathrm{K})$ e fósforo $(\mathrm{P})$ em diferentes sistemas de uso do solo. Cassilândia-MS, 2017.

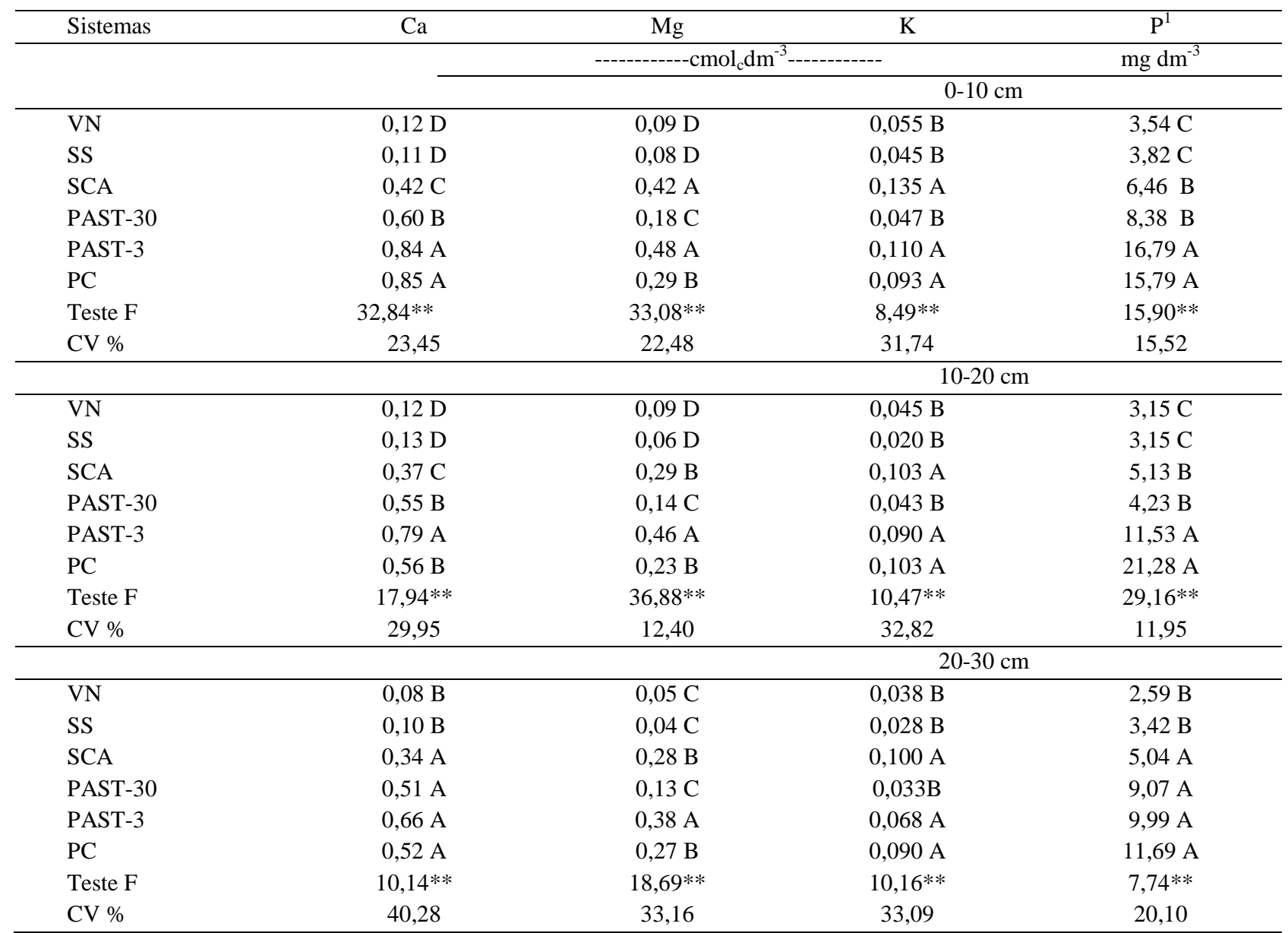

VN (Vegetação nativa), SS (seringueira solteira), SCA (seringueira consorciada com abacaxi), PAST-30 (área de pastagem com 30 anos), PAST-3 (área de pastagem reformada a 3 anos) e PC (área de plantio convencional). Médias seguidas de letras iguais na coluna não diferem entre si pelo teste de Scott-Knott $(\mathrm{p} \leq 0,05)$. Pelo Teste $\mathrm{F} * *$ significativo a $1 \%$ de probabilidade, *significativo a $5 \%$ de probabilidade, ${ }^{\text {ns }}$ não significativo. ${ }^{1}$ Dados transformados em $1 / \sqrt{ } x$, mais com médias originais apresentadas na tabela.

Souza e Alves (2003) observaram resultados semelhantes estudando modificações de propriedades químicas de um Latossolo Vermelho sob cerrado, sendo os menores teores de $\mathrm{P}$ relatados nos tratamentos cerrado, pastagem e seringueira. Os sistemas de uso do solo apresentaram para os valores de soma de bases (SB), capacidade de troca de cátions (CTC), saturação por alumínio (m\%) e saturação por bases (V\%) diferença significativa a $1 \%$ de probabilidade nas três camadas estudadas (Tabela 3 ).

Para os valores de SB nos diferentes sistemas de uso do solo, os valores observados variaram de 0,17 a $1,43 \mathrm{cmol}_{\mathrm{c}} \mathrm{dm}^{-3}$; valores classificados como muito baixos e baixos segundo Ribeiro et al. (1999). Na comparação entre os sistemas de uso do solo, os maiores valores de SB foram observados nas áreas de PAST-3 e PC na camada de $0-10 \mathrm{~cm}$. Na camada de 10-20 e 20-30 cm, apenas a área de PAST-3 apresentou os maiores teores diferindo estatisticamente dos demais sistemas (Tabela 3). Desta maneira é possível notar que as médias obtidas para a SB refletiram o comportamento das bases $(\mathrm{Ca}, \mathrm{Mg}, \mathrm{K})$ no solo em resposta aos manejos adotados (CARVALHO et al., 2015).

A área de VN apresentou os valores mais elevados de CTC em todas as camadas avaliadas diferindo significativamente dos demais sistemas de uso na camada de 0-10 e 10-20 cm, porém na camada de 20$30 \mathrm{~cm}$ não apresentou diferença significativa em relação à SS, SCA e PC (Tabela 3). Importante ressaltar que os altos valores de CTC observados na área de $\mathrm{VN}$, não são em decorrência da presença de bases trocáveis, uma vez que, os valores de SB foram baixos, e sim dos altos teores de acidez potencial $(\mathrm{H}+\mathrm{Al})$. Além disso, os valores de CTC observados nos sistemas de uso do solo estão classificados entre médio e baixo, indicando a baixa fertilidade deste solo (RIBEIRO et al., 1999). 
Tabela 3. Valores de soma de bases (SB), capacidade de troca de cátions a pH 7,0 (CTC), saturação por alumínio (m\%) e saturação por bases (V\%). Cassilândia-MS, 2017.

\begin{tabular}{|c|c|c|c|c|}
\hline Sistemas & SB & CTC & $\mathrm{m}$ & $\mathrm{V}$ \\
\hline & \multicolumn{2}{|c|}{---- $\mathrm{cmol}_{\mathrm{c}} \mathrm{dm}^{-3}$----- } & \multicolumn{2}{|c|}{$\%$} \\
\hline \multicolumn{5}{|c|}{$0-10 \mathrm{~cm}$} \\
\hline$\overline{\mathrm{VN}}$ & $0,28 \mathrm{C}$ & $7,89 \mathrm{~A}$ & $87,50 \mathrm{~A}$ & $3,49 \mathrm{D}$ \\
\hline SS & $0,23 \mathrm{C}$ & $5,96 \mathrm{~B}$ & $83,38 \mathrm{~A}$ & $3,95 \mathrm{D}$ \\
\hline SCA & $0,97 \mathrm{~B}$ & $6,30 \mathrm{~B}$ & $50,76 \mathrm{~B}$ & $15,58 \mathrm{C}$ \\
\hline PAST-30 & $0,84 \mathrm{~B}$ & $5,18 \mathrm{C}$ & $40,85 \mathrm{~B}$ & $16,81 \mathrm{C}$ \\
\hline PAST-3 & $1,43 \mathrm{~A}$ & $4,25 \mathrm{~B}$ & $13,80 \mathrm{C}$ & $33,53 \mathrm{~A}$ \\
\hline $\mathrm{PC}$ & $1,25 \mathrm{~A}$ & $5,31 \mathrm{C}$ & $27,82 \mathrm{C}$ & $24,04 \mathrm{~B}$ \\
\hline Teste F & $35,76^{* *}$ & $13,03 * *$ & $28,02 * *$ & $28,06 * *$ \\
\hline \multirow[t]{2}{*}{$\mathrm{CV} \%$} & 19,76 & 11,78 & 22,12 & 27,00 \\
\hline & \multicolumn{4}{|c|}{$10-20 \mathrm{~cm}$} \\
\hline$\overline{\mathrm{VN}}$ & $0,25 \mathrm{C}$ & $6,99 \mathrm{~A}$ & $86,35 \mathrm{~A}$ & $3,51 \mathrm{C}$ \\
\hline SS & $0,21 \mathrm{C}$ & $5,86 \mathrm{~B}$ & $86,75 \mathrm{~A}$ & $3,68 \mathrm{C}$ \\
\hline $\mathrm{SCA}$ & $0,76 \mathrm{~B}$ & $6,18 \mathrm{~B}$ & $60,32 \mathrm{~B}$ & $12,32 \mathrm{~B}$ \\
\hline PAST-30 & $0,73 \mathrm{~B}$ & $4,84 \mathrm{C}$ & $46,48 \mathrm{~B}$ & $15,73 \mathrm{~B}$ \\
\hline PAST-3 & $1,34 \mathrm{~A}$ & $4,30 \mathrm{C}$ & $11,49 \mathrm{C}$ & $31,30 \mathrm{~A}$ \\
\hline $\mathrm{PC}$ & $0,89 \mathrm{~B}$ & $5,26 \mathrm{C}$ & $51,92 \mathrm{~B}$ & $17,36 \mathrm{~B}$ \\
\hline Teste F & $25,65 * *$ & $13,62 * *$ & $33,57 * *$ & $23,30 * *$ \\
\hline \multirow[t]{2}{*}{$\mathrm{CV} \%$} & 24,02 & 9,43 & 16,99 & 30,61 \\
\hline & \multicolumn{4}{|c|}{$20-30 \mathrm{~cm}$} \\
\hline$\overline{\mathrm{VN}}$ & $0,17 \mathrm{C}$ & $6,09 \mathrm{~A}$ & $89,40 \mathrm{~A}$ & $2,84 \mathrm{C}$ \\
\hline SS & $0,17 \mathrm{C}$ & $5,74 \mathrm{~A}$ & $87,91 \mathrm{~A}$ & $3,01 \mathrm{C}$ \\
\hline SCA & $0,73 \mathrm{~B}$ & $6,16 \mathrm{~A}$ & $60,82 \mathrm{~B}$ & $11,79 \mathrm{~B}$ \\
\hline PAST-30 & $0,67 \mathrm{~B}$ & 4,63 B & 49,94 B & $15,04 \mathrm{~B}$ \\
\hline PAST-3 & $1,10 \mathrm{~A}$ & $4,20 \mathrm{~B}$ & $21,49 \mathrm{C}$ & $26,44 \mathrm{~A}$ \\
\hline PC & $0,88 \mathrm{~B}$ & $5,58 \mathrm{~A}$ & $61,84 \mathrm{~B}$ & $15,69 \mathrm{~B}$ \\
\hline Teste F & $14,84 * *$ & $9,50 * *$ & $19,91 * *$ & 17,00 \\
\hline $\mathrm{CV} \%$ & 31,65 & 9,64 & 8,34 & $34,55 * *$ \\
\hline
\end{tabular}

$\overline{\mathrm{VN}}$ (Vegetação nativa), SS (seringueira solteira), SCA (seringueira consorciada com abacaxi), PAST-30 (área de pastagem com 30 anos), PAST-3 (área de pastagem reformada a 3 anos) e PC (área de plantio convencional). Médias seguidas de letras iguais na coluna não diferem entre si pelo teste de Scott-Knott $(\mathrm{p} \leq 0,05)$. Pelo Teste $\mathrm{F} * *$ significativo a $1 \%$ de probabilidade, *significativo a $5 \%$ de probabilidade, ${ }^{\mathrm{s}}$ não significativo.

Para a saturação por alumínio (m\%), os maiores valores foram constados na área de VN e SS em todas as camadas avaliadas diferindo significativamente dos demais sistemas (Tabela 3). Tal comportamento está de acordo com os resultados observados para a acidez do solo. Nestes sistemas de uso do solo, os valores de $\mathrm{m} \%$ foram superiores a $60 \%$, indicando alta saturação por alumínio (RIBEIRO et al., 1999); elemento tóxico para as raízes e prejudicial para o crescimento e desenvolvimento das plantas cultivadas.

Para a saturação por bases (V\%), a área de VN e SS apresentaram os menores valores em comparação aos demais tratamentos em todas as camadas estudadas (Tabela 3). Por sua vez, o sistema PAST-3 apresentou os maiores valores para a $\mathrm{V} \%$ diferindo estatisticamente dos demais sistemas. Esses resultados são reflexos dos valores mais elevados de bases trocáveis que tal sistema apresentou, além dos maiores valores do $\mathrm{pH}$ e menor atuação do $\mathrm{H}+\mathrm{Al}$ nas características químicas do solo. No entanto, os valores de V\% foram inferiores a $40 \%$ em todos os sistemas de uso e em todas as camadas do solo, indicando baixa V\% (RIBEIRO et al., 1999). Estes resultados revelam que é necessária a realização de correções e adubações no solo para que o cultivo nestas áreas sejam favoráveis.

\section{Conclusões}

O sistema de pastagem de Brachiaria brizantha $\mathrm{cv}$. Marandu com 3 anos apresentou melhores resultados nos atributos químicos em razão do manejo da fertilidade realizado na área.

Os Neossolos Quartzarêncos na região do Cerrado apresentam baixa fertilidade natural e a variação dos atributos químicos do solo está relacionada principalmente com o manejo da adubação. Desta forma, recomenda-se realizar correções e adubações regularmente nestes solos para produção agrícola.

\section{Referências}

ARAÚJO, R.; GOEDERT, W. J.; LACERDA, M. P. C. Qualidade de um solo sob diferentes usos e sob cerrado nativo. Revista Brasileira de Ciência do Solo, Viçosa-MG, v. 31, n. 1, p. 1099-1108, 2007. 
CAIRES, E. F. Manejo da acidez do solo. In: PROCHNOW, L. I.; CASARIN, V.; STIPP, S. R. Boas práticas para uso eficiente de fertilizantes. Piracicaba-SP: IPNI, 2010, p. 276347.

CARNEIRO, M. A. C.; SOUZA, E. D.; REIS, E. F.; PEREIRA, H. S.; AZEVEDO, W. R. Atributos físicos, químicos e biológicos de solo de cerrado sob diferentes sistemas de uso e manejo. Revista Brasileira de Ciência do Solo, Viçosa-MG, v. 33, n. 1 p.147-157, 2009.

CARVALHO, R. P.; DANIEL, O.; DAVIDE, A. C.; SOUZA, F. R. Atributos físicos e químicos de um Neossolo Quartzarênico sob diferentes sistemas de uso e manejo. Revista Caatinga, Mossoró-RN, v. 28, n. 1, p. 148-159, 2015.

CLAESSEN, M. E. C. (Org.). Manual de métodos de análises de solo. 2. ed. Rio de Janeiro-RJ: Embrapa Solos, 1997, 212 p.

COSTA, C. D. O.; ALVES, M. C.; SOUSA, A. P. Atributos químicos dos solos sob diferentes usos e manejos em uma sub-bacia no noroeste do estado de São Paulo. Scientia Agraria Paranaensis, Marechal Cândido Rondon-PR, v. 14, n. 2, p. 119-126, 2015.

COSTA, G. S.; GAMA-RODRIGUES, A. C.; CUNHA, G. M. Decomposição e liberação de nutrientes da serapilheira foliar em povoamento de Eucalyptus grandis no norte fluminense. Revista Árvore, Viçosa-MG, v. 29, n. 4, p. 563$570,2005$.

FRAZÃO, L. A.; PÍCCOLO, M. C.; FEIGL, B. J. Propriedades químicas de um Neossolo Quartzarênico sob diferentes sistemas de manejo no Cerrado mato-grossense. Pesquisa Agropecuária Brasileira, Brasília-DF, v. 43, n. 5, p. 641-648, 2008.

KÖPPEN, W. Climatologia: con un estudio de los climas de la tierra. México: Fondo de Cultura Económica, 1948. 478 p.

MATIAS, M. C. B.; SALVIANO, A. A. C.; LEITE, L. F. C.; GALVÃO, S. R. S. Propriedades químicas em Latossolo Amarelo de Cerrado do Piauí sob diferentes sistemas de manejo. Revista Ciência Agronômica, Fortaleza-CE, v. 40, n. 3, p. 356-362, 2009.
PORTUGAL, A. F.; COSTA, O. V.; COSTA, L. M.; SANTOS, B. C. M. Características químicas e físicas de um Argissolo submetido a diferentes usos agrícolas. Revista Ceres, Viçosa-MG, v. 54, n. 315, p. 412-421, 2007.

RIBEIRO, A. C.; GUIMARAES, P. T. G.; ALVAREZ, V. V.. (Ed.). Recomendações para o uso de corretivos e fertilizantes em Minas Gerais: $5^{\circ}$ aproximação. ViçosaMG: Comissão de Fertilidade do Solo do Estado de Minas Gerais, 1999. 359 p.

SANTOS, H. G., JACOMINE, P. K. T., ANJOS, L. H. C., OLIVEIRA, V. A., LUBRERAS, J. F., COELHO, M.R., ALMEIDA, J. A., CUNHA, T. J. F.; OLIVEIRA, J. B. (ed.). Sistema Brasileiro de Classificação de Solos. 3. ed. Brasília-DF: Embrapa Solos, 2013, 353 p.

SANTOS, H. P.; TOMM, G. O. Disponibilidade de nutrientes e teor de matéria orgânica em função de sistemas de cultivo e de manejo de solo. Ciência Rural, Santa Maria-RS, v. 33, n. 3, p. 477-486, 2003.

SIQUEIRA NETO, M.; PICCOLO, M. C.; SCOPEL, E.; COSTA JUNIOR, C.; CERRI, C. C.; BERNOUX, M. Carbono total e atributos químicos com diferentes usos do solo no Cerrado. Acta Scientiarum. Agronomy, MaringáPR, v. 31, n. 4, p. 709-717, 2009.

SOUZA, G. S.; LIMA, J. S. S.; SILVA, S. A.; OLIVEIRA, R. B. Variabilidade espacial de atributos químicos em um Argissolo sob pastagem. Acta Scientiarum. Agronomy, Maringá-PR, v. 30, n. 4, p. 589-596, 2008.

SOUZA, Z. M.; ALVES, M. C. Propriedades químicas de um Latossolo vermelho distrófico de cerrado sob diferentes usos e manejos. Revista Brasileira de Ciência do Solo, ViçosaMG, v. 23, n. 27, p. 133-139, 2003.

VOLPE, E.; MARCHETTI, M. E.; MACEDO, M. C. M.; ROSA JUNIOR, E. J. Renovação de Pastagem degradada com calagem, adubação e leguminosa consorciada em Neossolo Quartzarênico. Acta Scientiarum. Agronomy, Maringá-PR, v. 30, n. 1, p. 131-138, 2008. 